\title{
Thermodynamic and Theoretical Study of the Preparation of New Buckyballs from Corannulene, Coronene, and Circulene
}

\author{
Hasan R. Obayes, ${ }^{1}$ Ghadah H. Alwan, ${ }^{2}$ Ahmed A. Al-Amiery, ${ }^{1,3}$ \\ Abdul Amir H. Kadhum, ${ }^{3}$ and Abu Bakar Mohamad ${ }^{3}$ \\ ${ }^{1}$ Applied Chemical Division, Applied Science Department, University of Technology, Baghdad, Iraq \\ ${ }^{2}$ Ministry of Sciences and Technology, Industrial Research \& Development Directorate, Industrial Applications Center, Baghdad, Iraq \\ ${ }^{3}$ Department of Chemical and Process Engineering, Faculty of Engineering and Built Environment, Universiti Kebangsaan Malaysia, \\ 43600 Bangi, Selangor, Malaysia
}

Correspondence should be addressed to Ahmed A. Al-Amiery; dr.ahmed1975@gmail.com

Received 29 July 2013; Revised 16 September 2013; Accepted 7 October 2013

Academic Editor: Mohammad Taghi Ahmadi

Copyright (C) 2013 Hasan R. Obayes et al. This is an open access article distributed under the Creative Commons Attribution License, which permits unrestricted use, distribution, and reproduction in any medium, provided the original work is properly cited.

We applied density functional theory (DFT) to study three polycyclic aromatic compounds (PAHs), corannulene, coronene, and circulene, for the preparation of twelve new buckyballs with molecular dimensions of less than a nanometer. The results showed that the corannulene molecule is bowl-shaped, the coronene molecule is planar, and the circulene molecule has a unique saddle-shaped structure. Cyclic polymerization of the three molecules can be used to prepare new buckyballs, and this process produces hydrogen molecules. The most symmetric buckyball is also the most stable based on the values of the HOMO energy levels and has the most efficient gap energy, making it potentially useful for solar cell applications.

\section{Introduction}

Polycyclic aromatic hydrocarbons (PAHs) are a class of unique compounds that consist of fused, conjugated aromatic rings that do not contain heteroatoms or carry substituents [1]. Alternate PAHs contain only six-membered rings, and certain alternant PAHs are called "benzenoid" PAHs. "Small" and "large" PAHs contain up to or more than six fused aromatic rings, respectively. Most research has focused on small PAHs due to their availability [2]. Corannulene has the shape of a bowl because it contains a five-membered ring, which inverts rapidly. In addition to its nonstandard geometry and dynamic behavior, this molecule has attracted considerable interest as an important building block for the synthesis of $\mathrm{C}_{53}$. Additionally, the solid state packing behavior of corannulene is interesting [3]. As discussed in detail by Kawasa and Kurata, [4] not only bowl-shaped but also balland belt-shaped aromatic systems provide an exciting opportunity to study concave-convex interactions. Coronene (6circulene) is an aromatic planar symmetric molecule, which has been studied, synthesized, and well characterized [5].
Both corannulene and coronene have interesting conductive properties due to their large electronic resonance. Circulene, the next member of this molecular family, consists of a central cyclooctatetraene fragment surrounded by phenyl rings. Despite the efforts of researchers [6], circulene has not yet been synthesized. Several theoretical studies [7], but no detailed studies, have been carried out on the structure of this molecule. Theoretical predictions of the existence of buckyball molecules appeared in the late 1960s and early 1970s, but these predictions were largely unnoticed. The discovery of buckyballs was unexpected because the scientists were producing carbon plasmas to replicate and characterize unidentified interstellar matter. Mass spectrometry analysis of their product indicated the formation of spheroidal carbon molecules [8].

\section{The Calculation Method}

To calculate ground-state geometries, Gaussian 03, Revision C.01 [9] was optimized to a local minimum without 

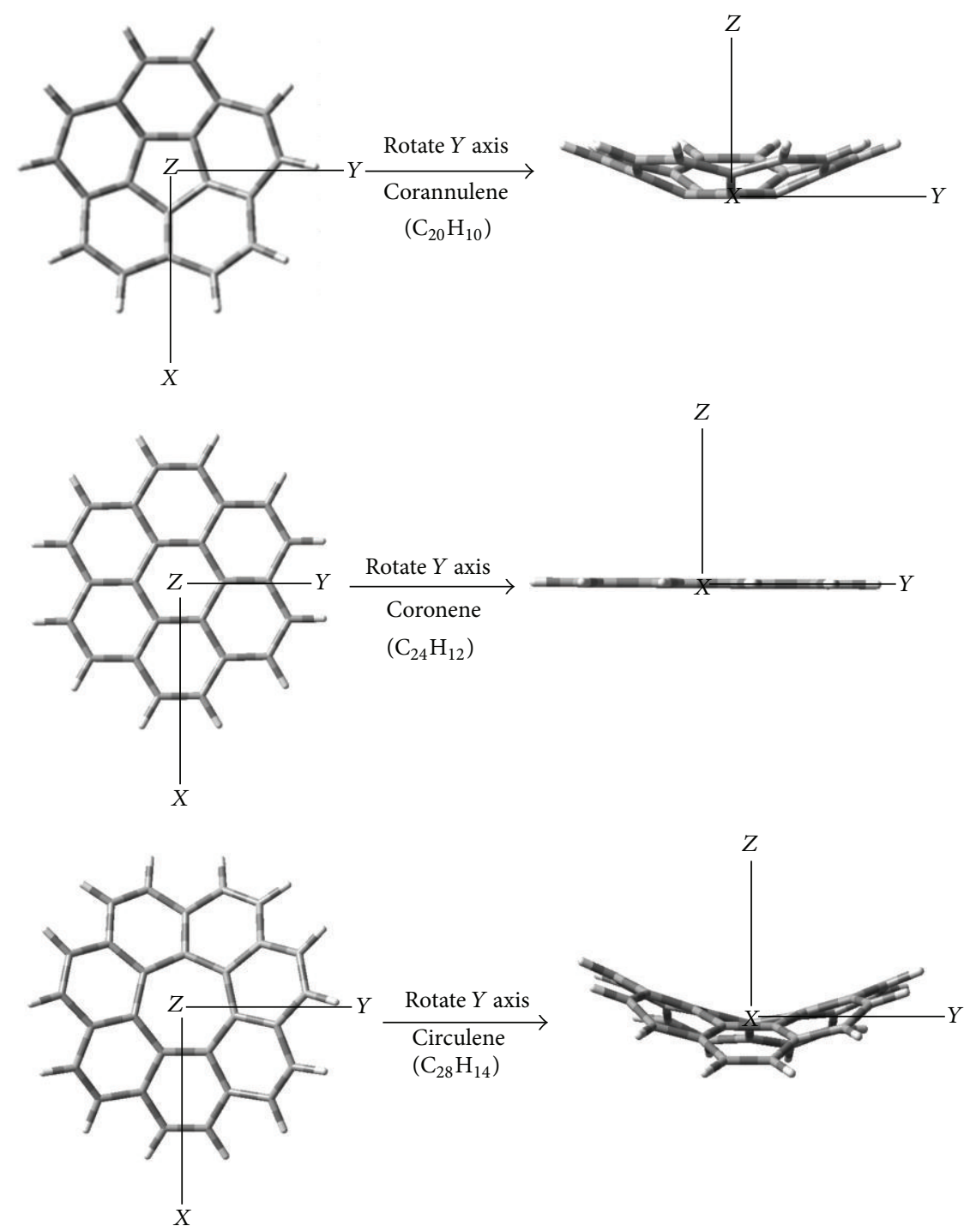

FIGURE 1: B3LYP/6-31G optimized structures of corannulene, coronene, and circulene.

symmetry restrictions using basis set $6-31 \mathrm{G}[10,11]$. The combination of the Becke three-parameter hybrid (B3) [12, 13] exchange functional and the Lee-Yang-Parr (LYP) [14] correlation functional (B3LYP) $[15,16]$ was used for all geometry optimizations, thermodynamic functions (at 298.150 Kelvin and $1.0 \mathrm{~atm}$ ), Highest Occupied Molecular Orbital Energies $\left(\mathrm{E}_{\mathrm{HOMO}}\right)$, Lowest Unoccupied Molecular Orbital Energies $\left(\mathrm{E}_{\mathrm{LUMO}}\right)$, and physical properties for the molecules in this study.

\section{Results and Discussion}

Previous studies have shown that not all polycyclic aromatic hydrocarbons (PAHs) are flat molecules. We selected aromatic compounds known as circulenes for this study. The circulenes include 5-circulene (corannulene), 6-circulene (coronene), and 7-circulene (circulene). According to Density Function Theory (DFT) calculations, not all of these molecules are flat, as shown in Figure 1. Corannulene is bowlshaped, coronene is planar, and circulene has a unique saddleshaped structure, which are consistent with the literature.

3.1. Density Function Theory (DFT). A DFT calculation introduces an additional step to each major phase of a HartreeFock calculation. This additional step is a numerical integration of the functional (or various derivatives of the functional). Thus, in addition to the sources of numerical error in Hartree-Fock calculations (integral accuracy, SCF convergence, and CPHF convergence), the accuracy of DFT calculations also depends on the number of points used in the numerical integration. The "fine" integration grid is the default in Gaussian 03. This grid greatly enhances the calculation accuracy at minimal additional cost. We do not recommend using a smaller grid in production DFT calculations. It is important to use the same grid for all calculations when energies will be compared (e.g., computing 


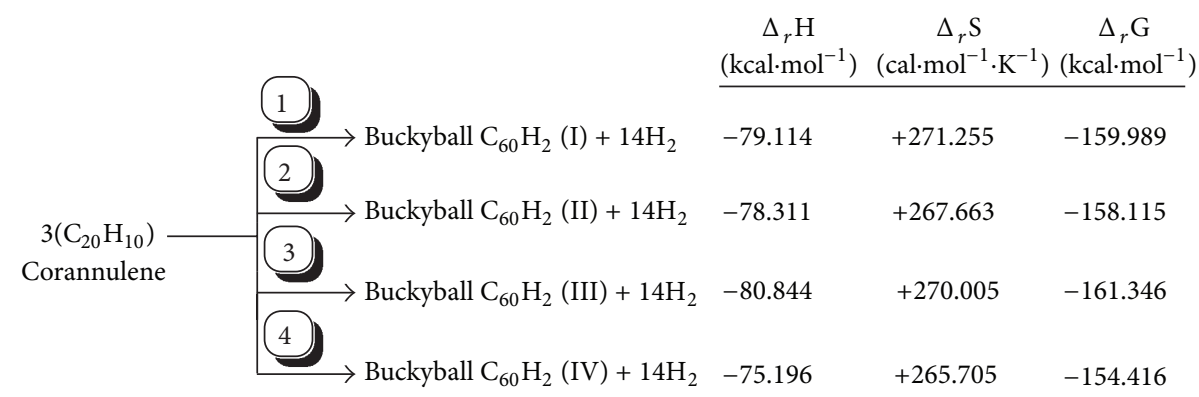

SCHEME 1: The reaction of formation of buckyball $\mathrm{C}_{60} \mathrm{H}_{2}$ from three molecules of corannulene and the values of the change of enthalpy $\left(\Delta_{r} \mathrm{H}\right)$, the change of entropy $\left(\Delta_{r} S\right)$, and the change of Gibbs energy $\left(\Delta_{r} G\right)$.

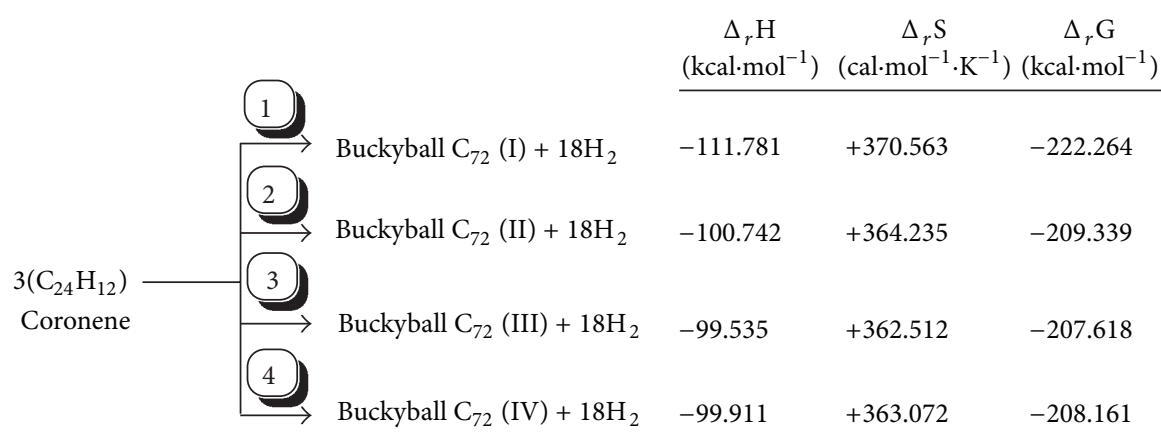

Scheme 2: The reaction of formation of buckyball $\mathrm{C}_{72}$ from three molecules of coronene and the values of $\Delta_{r} \mathrm{H}, \Delta_{r} \mathrm{~S}$ and $\Delta_{r} \mathrm{G}$.

energy differences, heats of formation, and so forth). Larger grids are available, for example, for tight optimization of certain systems. An alternate grid may be selected in the route section [17-20].

To prepare new buckyballs, a fundamental understanding of the polymerization of polycyclic aromatic hydrocarbons (PAHs) is important. The polymerization process for new buckyballs revealed the production of hydrogen molecules $[21,22]$, and the general reaction of formation of new buckyballs from three molecules of polycyclic aromatic hydrocarbons (PAHs) is as follows,

$$
3\left[\begin{array}{c}
\text { Polycyclic aromatic } \\
\text { hydrocarbons } \\
\left(\mathrm{C}_{n} \mathrm{H}_{(1 / 2) n}\right) \\
{[\mathrm{PAHs}]}
\end{array}\right] \longrightarrow \text { Buckyball }\left[\mathrm{C}_{3 n} \mathrm{H}_{m}\right]+x \mathrm{H}_{2},
$$

where $n$ is number of carbon atoms, $x$ is $(3 / 4) n-(1 / 2) m, m$ is 2 in corannulene and circulene, and $m$ is 0 in coronene.

\subsubsection{The Cyclic Polymerization of Three Corannulene Mol-} ecules. Scheme 1 shows all possible cyclic polymerization reactions of three molecules of corannulene. Reaction (1) produced a new buckyball $\mathrm{C}_{60} \mathrm{H}_{2}$ (I) by forming five butagons, three pentagons, three hexagons, and two decagon cycles from three corannulene molecules. Reaction (2) produced a new buckyball $\mathrm{C}_{60} \mathrm{H}_{2}$ (II) through the formation of three butagons, five pentagons, three hexagons, and two nonagon cycles. Reaction (3) produced a new buckyball $\mathrm{C}_{60} \mathrm{H}_{2}$ (III) by forming three butagons, three pentagons, five hexagons, and two octagon cycles. Reaction (4) produced a new buckyball $\mathrm{C}_{60} \mathrm{H}_{2}$ (IV) by forming eleven pentagons and two nonagon cycles. Thirteen different cycles were formed in these four reactions. All of these reactions are spontaneous and exothermic according to the values of the entropy change $\left(\Delta_{r} S\right)$, the Gibbs energy change $\left(\Delta_{r} G\right)$, and the enthalpy change $\left(\Delta_{r} \mathrm{H}\right)$. The results for the $\mathrm{E}_{\mathrm{HOMO}}$ (the Energy of High Occupied Molecular Orbital) and the total energy for the four reaction products in Table 1 reveal that the products are stable, that the new buckyball $\mathrm{C}_{60} \mathrm{H}_{2}$ (IV) is the most stable among the four, and that the increase in the $\mathrm{E}_{\mathrm{HOMO}}$ for $\mathrm{C}_{60} \mathrm{H}_{2}(\mathrm{IV})$ is $(-0.4530 \mathrm{eV}),(-0.6177 \mathrm{eV})$, and $(-0.6236 \mathrm{eV})$ relative to $\mathrm{C}_{60} \mathrm{H}_{2}$ (I), $\mathrm{C}_{60} \mathrm{H}_{2}$ (II), and $\mathrm{C}_{60} \mathrm{H}_{2}$ (III) respectively. Additionally, the increase in the total energy is -0.1978 a.u or $-124.121 \mathrm{KCal} \cdot \mathrm{mol}^{-1},-0.1365 \mathrm{a}$.u or $-85.655 \mathrm{KCal} \cdot \mathrm{mol}^{-1}$, and -0.2260 a.u or $-141.817 \mathrm{KCal} \cdot \mathrm{mol}^{-1}$ for $\mathrm{C}_{60} \mathrm{H}_{2}$ (I), $\mathrm{C}_{60} \mathrm{H}_{2}$ (II), and $\mathrm{C}_{60} \mathrm{H}_{2}$ (III), respectively. The structures of the four new buckyballs are shown in Figure 2.

The molecular dimensions of the four new buckyballs are as follows: $\mathrm{C}_{60} \mathrm{H}_{2}$ (I) $-(0.85 x$-axis, $0.75 y$-axis, and $0.52 z$ axis) $\mathrm{nm}, \mathrm{C}_{60} \mathrm{H}_{2}$ (II) $-(0.83 x$-axis, $0.73 y$-axis, and $0.49 z$ axis) $\mathrm{nm}, \mathrm{C}_{60} \mathrm{H}_{2}$ (III) - $(0.84 x$-axis, $0.72 y$-axis, and $0.48 z$ axis) $\mathrm{nm}$, and $\mathrm{C}_{60} \mathrm{H}_{2}$ (IV) $-(0.84 x$-axis, $0.73 y$-axis, and 0.48 $z$-axis) $\mathrm{nm}$.

3.1.2. The Cyclic Polymerization of Three Molecules of Coronene. Scheme 2 shows all possible cyclic polymerization reactions of three molecules of coronene. Reaction (1) produced a new buckyball $\mathrm{C}_{72}$ (I) and forms nine butagons, six hexagons, and two nonagon cycles from the three 
TABLE 1: Physical values of all new buckyballs were calculated with B3LYP/6-31G.

\begin{tabular}{|c|c|c|c|c|c|c|}
\hline Molecules & $\begin{array}{c}\text { Total energy } \\
\text { a.u. }\end{array}$ & 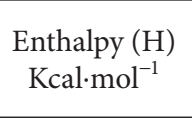 & $\begin{array}{c}\text { Entropy }(\mathrm{S}) \\
\mathrm{Cal} \cdot \mathrm{mol}^{-1} \cdot \mathrm{K}^{-1}\end{array}$ & $\begin{array}{c}\mathrm{E}_{\text {HOMо }} \\
\mathrm{eV}\end{array}$ & $\begin{array}{c}\mathrm{E}_{\text {LUMO }} \\
\mathrm{eV}\end{array}$ & $\begin{array}{c}\text { Gap energy } \\
\left(\mathrm{E}_{\mathrm{LUMO}}-\mathrm{E}_{\mathrm{HOMO}}\right) \\
\mathrm{eV}\end{array}$ \\
\hline Hydrogen molecule $\left(\mathrm{H}_{2}\right)$ & -1.1755 & 7.847 & 31.132 & -11.8086 & +2.7235 & 14.5321 \\
\hline Corannulene & -767.9696 & 154.105 & 103.100 & -6.0170 & -1.5783 & 4.4387 \\
\hline Buckyball $\mathrm{C}_{60} \mathrm{H}_{2}$ (I) & -2286.0419 & 273.343 & 144.707 & -5.4453 & -3.9097 & 1.5356 \\
\hline Buckyball $\mathrm{C}_{60} \mathrm{H}_{2}$ (II) & -2286.1032 & 274.146 & 141.115 & -5.2806 & -3.9288 & 1.3518 \\
\hline Buckyball $\mathrm{C}_{60} \mathrm{H}_{2}$ (III) & -2286.0137 & 271.613 & 143.457 & -5.2747 & -4.2510 & 1.0237 \\
\hline Buckyball $\mathrm{C}_{60} \mathrm{H}_{2}(\mathrm{IV})$ & -2286.2397 & 277.261 & 139.157 & -5.8983 & -3.7968 & 2.1015 \\
\hline Coronene & -921.6885 & 185.772 & 115.845 & -5.4880 & -1.4049 & 4.0831 \\
\hline 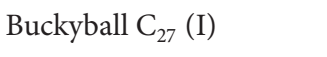 & -2741.7592 & 304.289 & 157.722 & -4.9922 & -3.9154 & 1.0768 \\
\hline 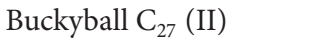 & -2742.1237 & 315.328 & 151.394 & -5.2425 & -4.1043 & 1.1382 \\
\hline Buckyball C $_{27}$ (III) & -2741.9284 & 316.535 & 149.671 & -5.0902 & -4.2567 & 0.8335 \\
\hline Buckyball C $_{27}$ (IV) & -2742.1856 & 316.159 & 150.231 & -5.7024 & -3.3212 & 2.3812 \\
\hline Circulene & -1075.2072 & 216.027 & 132.547 & -5.1430 & -1.4348 & 3.7082 \\
\hline Buckyball $\mathrm{C}_{84} \mathrm{H}_{2}(\mathrm{I})$ & -3199.7795 & 372.282 & 180.179 & -5.2175 & -3.6338 & 1.5837 \\
\hline Buckyball $\mathrm{C}_{84} \mathrm{H}_{2}$ (II) & -3199.9262 & 374.865 & 176.142 & -5.2404 & -3.7780 & 1.4624 \\
\hline Buckyball $\mathrm{C}_{84} \mathrm{H}_{2}$ (III) & -3199.9163 & 374.917 & 174.315 & -5.0417 & -4.0741 & 0.9676 \\
\hline Buckyball $\mathrm{C}_{84} \mathrm{H}_{2}$ (IV) & -3200.2067 & 381.333 & 170.827 & -5.7372 & -3.8110 & 1.9262 \\
\hline
\end{tabular}

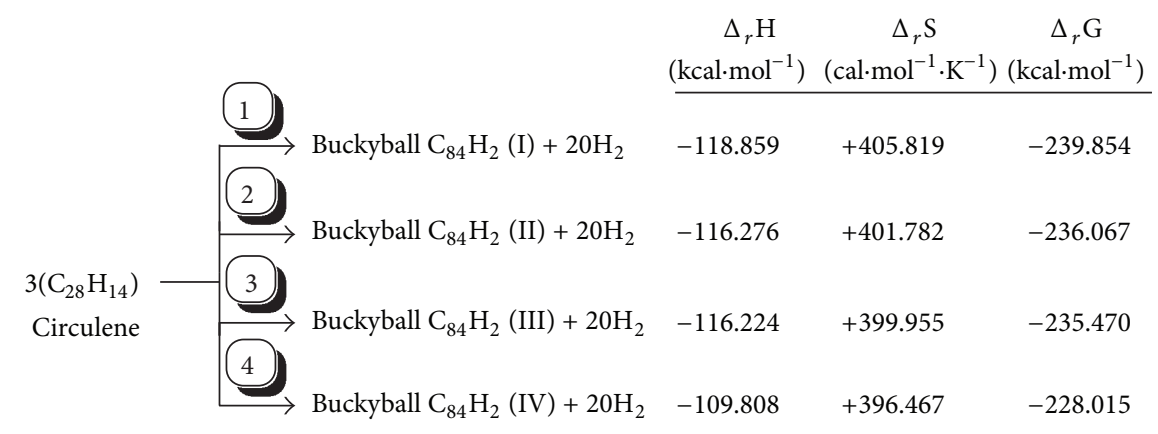

Scheme 3: The reaction of formation of $\mathrm{C}_{84} \mathrm{H}_{2}$ buckyballs from three molecules of circulene and the values of $\Delta_{r} \mathrm{H}, \Delta_{r} \mathrm{~S}$ and $\Delta_{r} \mathrm{G}$.

coronene molecules. Reaction (2) produced a new buckyball $\mathrm{C}_{72}$ (II) by forming three butagons, ten pentagons, two hexagons, and two octagon cycles. Reaction (3) produced a new buckyball $\mathrm{C}_{72}$ (III) and formed two butagons, ten pentagons, three hexagons, and two heptagon cycles. Reaction (4) produced a new buckyball $\mathrm{C}_{72}$ (IV) and formed six butagons, and eleven hexagon cycles. Seventeen cycles were formed in each reaction. Every reaction is spontaneous and exothermic according to the values of $\Delta_{r} \mathrm{~S}, \Delta_{r} \mathrm{G}$, and $\Delta_{r} \mathrm{H}$. The $\mathrm{E}_{\mathrm{HOMO}}$ and the total energy for the four reaction products in Table 1 reveal that the products are stable, that the new buckyball $\mathrm{C}_{72}$ (IV) is the most stable among the four, and that the increase in $\mathrm{E}_{\mathrm{HOMO}}$ for $\mathrm{C}_{72}$ (IV) is $(-0.7102 \mathrm{eV}),(-0.4599 \mathrm{eV})$, and $(-0.6122 \mathrm{eV})$ relative to new buckyballs $\mathrm{C}_{72}$ (I), $\mathrm{C}_{72}$ (II) and $\mathrm{C}_{72}$ (III), respectively. Additionally, the increases in total energy are -0.4264 a.u or $-267.570 \mathrm{KCal} \cdot \mathrm{mol}^{-1},-0.0619$ a.u or $-38.843 \mathrm{KCal} \cdot \mathrm{mol}^{-1}$, and $-0.2572 \mathrm{a}$.u or $-161.395 \mathrm{KCal} \cdot \mathrm{mol}^{-1}$ for new buckyballs
$\mathrm{C}_{72}$ (I), $\mathrm{C}_{72}$ (II), and $\mathrm{C}_{72}$ (III), respectively. The structures of the four new buckyballs are shown in Figure 3.

The molecular dimensions of all four new $\mathrm{C}_{72}$ buckyballs are as follows: $\mathrm{C}_{72}(\mathrm{I})-(0.82 x$-axis, $0.80 y$-axis, and 0.52 $z$-axis $) \mathrm{nm}, \mathrm{C}_{72}$ (II) - $(0.83 x$-axis, $0.78 y$-axis, and $0.55 z$ axis) $\mathrm{nm}, \mathrm{C}_{72}$ (III) - $(0.88 x$-axis, $0.77 y$-axis, and $0.55 z$ axis) $\mathrm{nm}$, and $\mathrm{C}_{72}(\mathrm{IV})-(0.82 x$-axis, $0.79 y$-axis, and 0.56 $z$-axis) nm.

3.1.3. The Cyclic Polymerization for Three Molecules of Circulene. Scheme 3 shows all possible cyclic polymerization reactions of three molecules of circulene. Reaction (1) produced a new buckyball $\mathrm{C}_{84} \mathrm{H}_{2}$ (I) by forming seven butagons, five pentagons, five hexagons, and two decagon cycles from three circulene molecules. Reaction (2) produced a new buckyball $\mathrm{C}_{84} \mathrm{H}_{2}$ (II) by forming five butagons, seven pentagons, five hexagons, and two nonagon cycles. Reaction (3) produced 


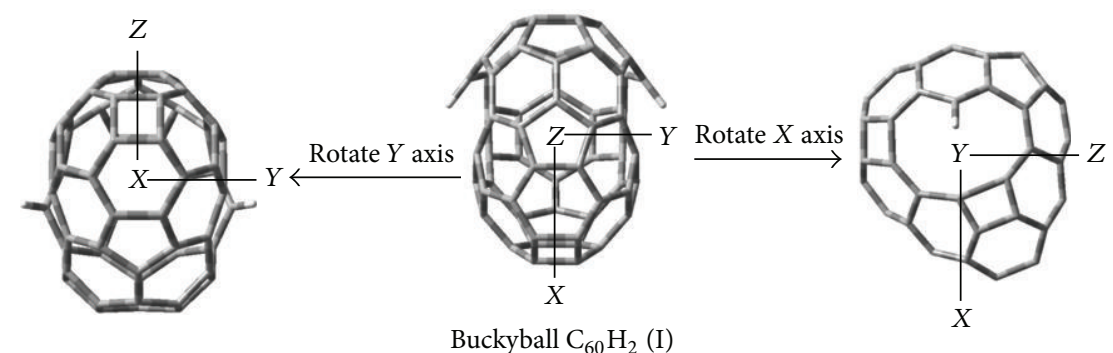

(a)

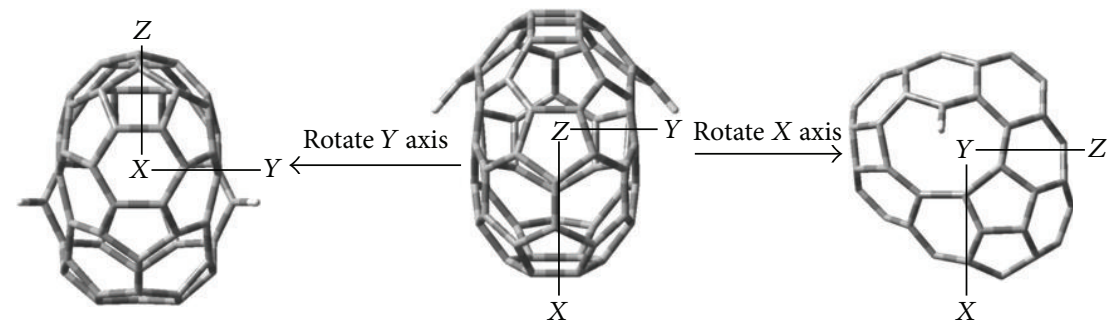

Buckyball $\mathrm{C}_{60} \mathrm{H}_{2}$ (II)

(b)

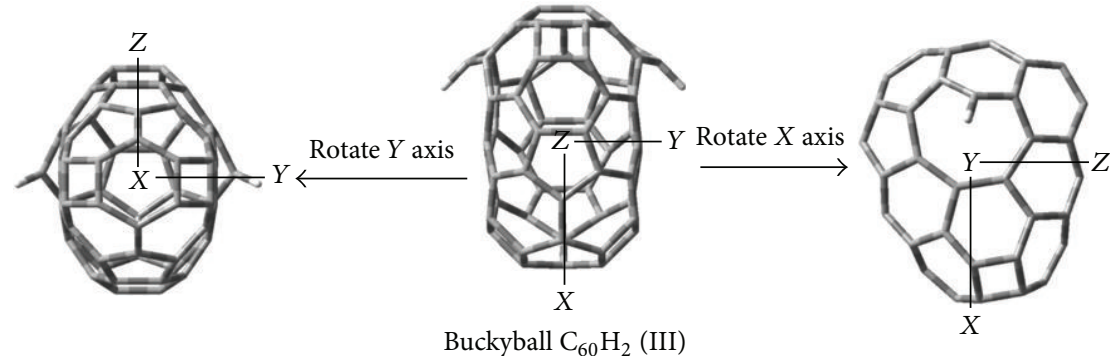

(c)

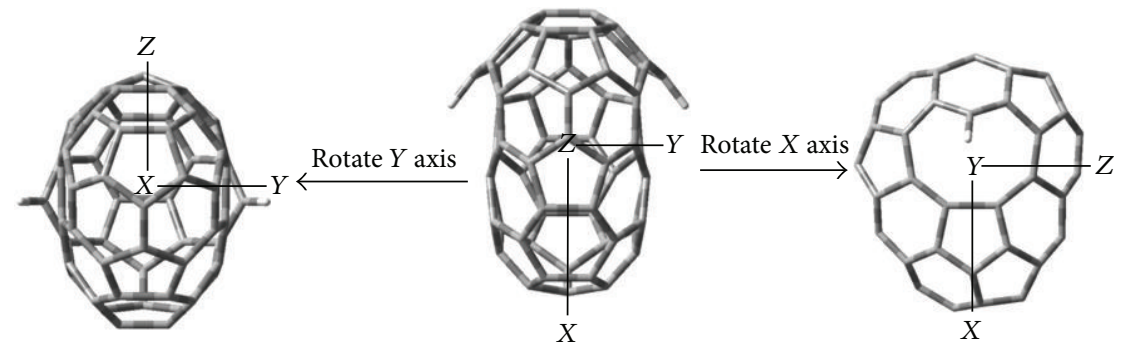

Buckyball $\mathrm{C}_{60} \mathrm{H}_{2}$ (IV)

(d)

FIGURE 2: B3LYP/6-31G optimized structures of four new buckyballs: $\mathrm{C}_{60} \mathrm{H}_{2}$ (I), $\mathrm{C}_{60} \mathrm{H}_{2}$ (II), $\mathrm{C}_{60} \mathrm{H}_{2}$ (III), and C $\mathrm{C}_{60} \mathrm{H}_{2}$ (IV).

a new buckyball $\mathrm{C}_{84} \mathrm{H}_{2}$ (III) and formed five butagons, five pentagons, seven hexagons, and two octagon cycles. Reaction (4) produced a new buckyball $\mathrm{C}_{84} \mathrm{H}_{2}$ (IV), seventeen pentagons, and two nonagon cycles. Nineteen different cycles were formed in each reaction. All of these reactions are spontaneous and exothermic according to the values of the change of entropy $\left(\Delta_{r} S\right)$, the change of Gibbs energy $\left(\Delta_{r} G\right)$, and the change of enthalpy $\left(\Delta_{r} \mathrm{H}\right)$. However, the the Energy of the Highest Occupied Molecular Orbital $\left(\mathrm{E}_{\mathrm{HOMO}}\right)$ and the total energy for the reaction products in Table 1 reveal that the product has more stability, in this state the product new buckyball $\mathrm{C}_{84} \mathrm{H}_{2}$ (IV), most stable among the four new buckyballs, was $\mathrm{C}_{84} \mathrm{H}_{2}$ (IV) with an increase in the $\mathrm{E}_{\mathrm{HOMO}}$, that is $(-0.5197 \mathrm{eV}),(-0.4968 \mathrm{eV})$, and $(-0.6955 \mathrm{eV})$ relative to $\mathrm{C}_{84} \mathrm{H}_{2}$ (I), $\mathrm{C}_{84} \mathrm{H}_{2}$ (II), and $\mathrm{C}_{84} \mathrm{H}_{2}$ (III), respectively. Additionally, the increases in total energy are -0.4272 a.u or $-268.072 \mathrm{KCal} \cdot \mathrm{mol}^{-1},-0.2805 \mathrm{a} . \mathrm{u}$ or $-176.016 \mathrm{KCal} \cdot \mathrm{mol}^{-1}$, and $-0.2904 \mathrm{a} . \mathrm{u}$ or $-182.228 \mathrm{KCal} \cdot \mathrm{mol}^{-1}$ relative to $\mathrm{C}_{84} \mathrm{H}_{2}$ (I), $\mathrm{C}_{84} \mathrm{H}_{2}$ (II) and $\mathrm{C}_{84} \mathrm{H}_{2}$ (III), respectively. The structures of the four new $\mathrm{C}_{84} \mathrm{H}_{2}$ buckyballs are shown in Figure 4. The molecular dimensions of all four new $\mathrm{C}_{84} \mathrm{H}_{2}$ buckyballs are as follows: $\mathrm{C}_{84} \mathrm{H}_{2}(\mathrm{I})-(0.86 x$-axis, $0.85 y$-axis, and 


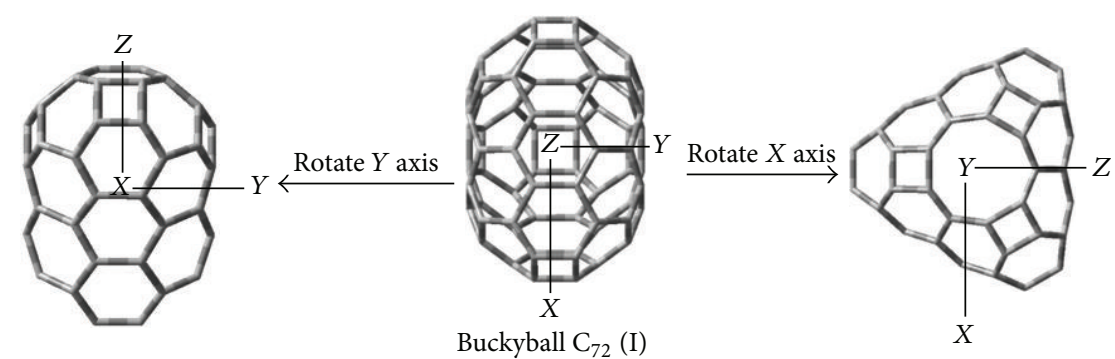

(a)
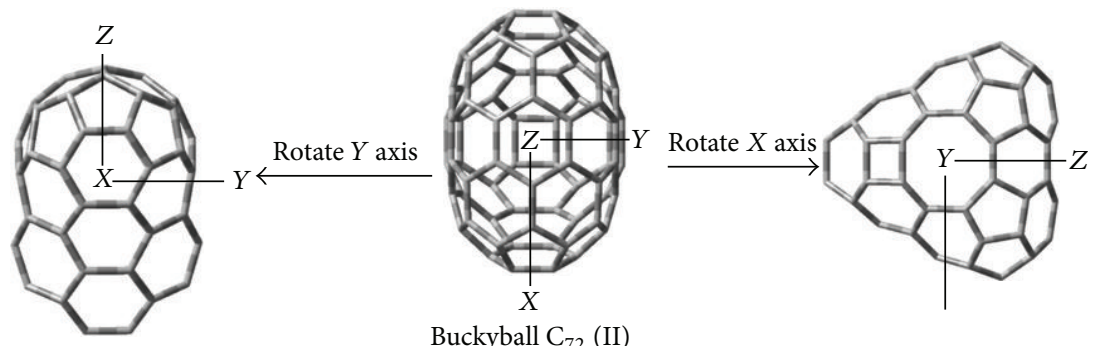

Buckyball $\mathrm{C}_{72}$ (II)

(b)

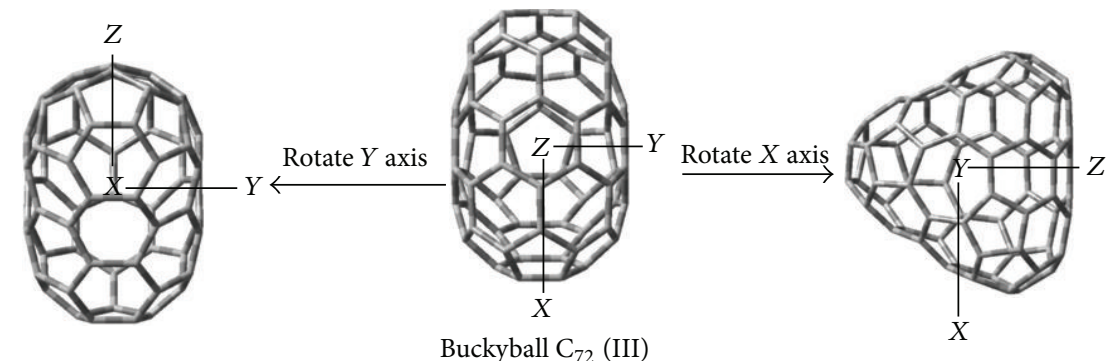

(c)

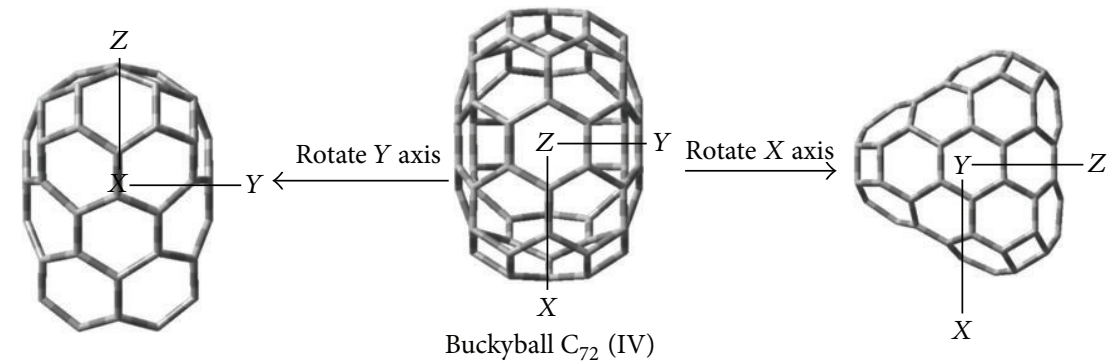

(d)

Figure 3: B3LYP/6-31G optimized structures of new buckyballs $\mathrm{C}_{72}$ (I), $\mathrm{C}_{72}$ (II), $\mathrm{C}_{72}$ (III), and $\mathrm{C}_{72}$ (IV).

$0.66 z$-axis $) \mathrm{nm}, \mathrm{C}_{84} \mathrm{H}_{2}$ (II) $-(0.90 x$-axis, $0.88 y$-axis, and $0.61 z$-axis $) \mathrm{nm}, \mathrm{C}_{84} \mathrm{H}_{2}$ (III) $-(0.89 x$-axis, $0.87 y$-axis, and $0.60 z$-axis $) \mathrm{nm}$, and $\mathrm{C}_{84} \mathrm{H}_{2}(\mathrm{IV})-(0.90 x$-axis, $0.87 y$-axis, and $0.60 z$-axis) $\mathrm{nm}$.

3.2. Energy Gap. The energy gap, which is also called the band gap, is an energy range in a solid where no electron states can exist. The gap energy generally refers to the energy difference (in electron volts) between the Lowest Unoccupied Molecular Orbital (LUMO) and the Highest Occupied Molecular Orbital (HOMO) in insulators and semiconductors. This gap energy is equivalent to the energy required to free an outer shell electron from its orbit about the nucleus to become a mobile charge carrier that moves freely within the solid material. The band gap is a major factor that determines the electrical conductivity of a solid. Substances with large gap energies are generally insulators, materials with smaller gap energies are semiconductors, and conducting materials have very small or no gaps energies. The Shockley-Queisser limit gives the maximum possible efficiency of single junction solar cells under unconcentrated sunlight as a function of the semiconductor band gap. If the band gap is too high, then the material cannot absorb most daylight photons; if the band gap is too low, then most photons have much more energy than 


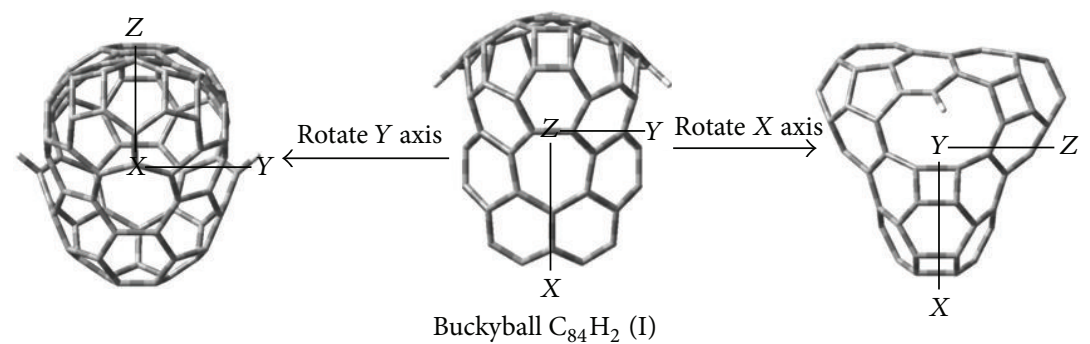

(a)

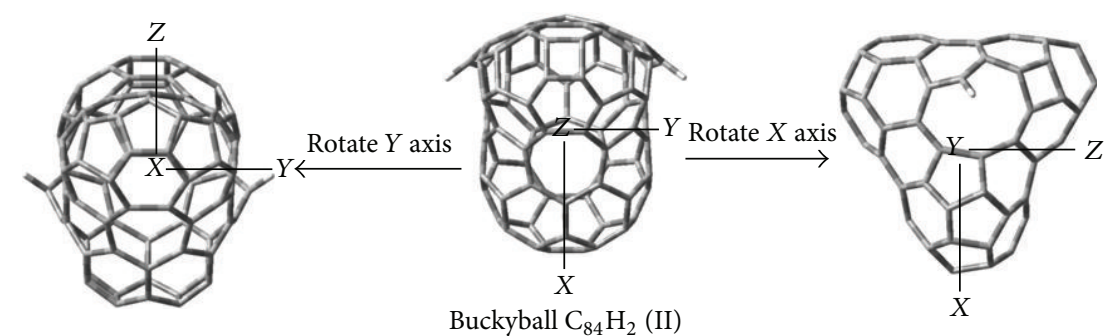

(b)

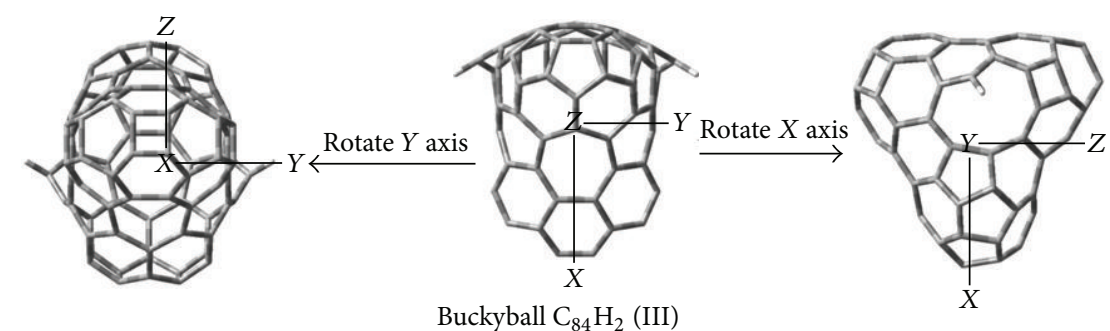

(c)

Figure 4: B3LYP/6-31G optimized structures of new buckyballs $\mathrm{C}_{84} \mathrm{H}_{2}$ (I), buckyballs $\mathrm{C}_{84} \mathrm{H}_{2}(\mathrm{II}), \mathrm{C}_{84} \mathrm{H}_{2}$ (III), and C ${ }_{84} \mathrm{H}_{2}$ (IV).

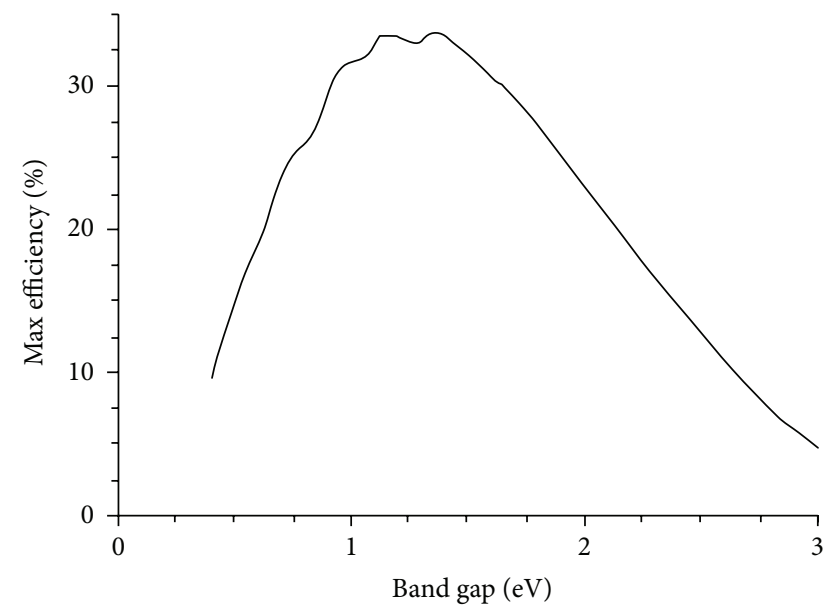

Figure 5: The Shockley-Queisser limit for the energy efficiency of a gap.

is necessary to excite electrons across the band gap, and the rest is wasted. The semiconductors that are used commonly in commercial solar cells have band gaps near the peak of this curve shown in Figure 5.
In Table 1, the values of the energy gaps for all buckyballs in the (0.8335-2.3812) eV range, arranged by the increases in energy gap, are as follows:

$$
\begin{aligned}
\text { Buckyball } \mathrm{C}_{27}(\mathrm{III}) & <\text { Buckyball } \mathrm{C}_{84} \mathrm{H}_{2} \text { (III) } \\
& <\text { Buckyball } \mathrm{C}_{60} \mathrm{H}_{2} \text { (III) } \\
& <\text { Buckyball } \mathrm{C}_{27} \text { (I) } \\
& <\text { Buckyball } \mathrm{C}_{27} \text { (II) } \\
& <\text { Buckyball } \mathrm{C}_{60} \mathrm{H}_{2} \text { (II) } \\
& <\text { Buckyball } \mathrm{C}_{84} \mathrm{H}_{2} \text { (II) } \\
& <\text { Buckyball } \mathrm{C}_{60} \mathrm{H}_{2} \text { (I) } \\
& <\text { Buckyball } \mathrm{C}_{84} \mathrm{H}_{2} \text { (I) } \\
& <\text { Buckyball } \mathrm{C}_{84} \mathrm{H}_{2} \text { (IV) } \\
& <\text { Buckyball } \mathrm{C}_{60} \mathrm{H}_{2} \text { (IV) } \\
& <\text { Buckyball } \mathrm{C}_{27}(\text { IV) }
\end{aligned}
$$




\section{Conclusions}

A quantum chemistry calculation is performed using the Density Function Theory (DFT) method to study the preparation of twelve new buckyballs from the cyclic polymerization of three polycyclic aromatic hydrocarbons (PAHs), corannulene, coronene, and circulene, and the production of hydrogen molecules. The results obtained for the new buckyballs show that the most symmetric buckyball is the most stable, depending on the values of $\mathrm{E}_{\mathrm{HOMO}}$. The molecular dimensions of all the new buckyballs are less than a nanometer, and the new buckyballs are characterized by the high efficiency of their energy gaps.

\section{Conflict of Interests}

The authors declare that there is no conflict of interests regarding the publication of this paper.

\section{References}

[1] J. C. Fetzer, The Chemistry and Analysisof the Large Polycyclic Aromatic Hydrocarbons, John Wiley, New York, NY, USA, 2000.

[2] X. Feng, W. Pisula, and K. Müllen, "Large polycyclic aromatic hydrocarbons: synthesis and discotic organization," Pure and Applied Chemistry, vol. 81, no. 12, pp. 2203-2224, 2009.

[3] Y. T. Wu and J. S. Siegel, "Aromatic molecular-bowl hydrocarbons: synthetic derivatives, their structures, and physical properties," Chemical Reviews, vol. 106, pp. 4843-4867, 2006.

[4] T. Kawasa and H. Kurata, "Ball-, bowl-, and belt-shaped conjugated systems and their complexing abilities: exploration of the concave-Convex $\pi-\pi$ interaction," Chemical Reviews, vol. 106, pp. 5250-5273, 2006.

[5] J. C. Hanson and C. E. Nordman, "The crystal and molecular structure of corannulene, $\mathrm{C}_{20} \mathrm{H}_{10}$, Acta Crystallographica, vol. B32, p. 1147, 1976.

[6] K. Yano, M. Osatani, and K. Tani, "On atempted synthesis of 8shaped circulene: synthesis and characterization of $[2,2]\left(4,4^{\prime}\right)$ biphenylo-(3,11)-dihenzo[c.l]chrysenophane and its cyclophadiene," Bulletin of the Chemical Society of Japan, vol. 73, pp. 185$189,2000$.

[7] T. Liljefors and O. Wennerstrom, "Molecular mechanics calculations on the structures and conformational properties of [8]circulene and some related phane compounds," Tetrahedron, vol. 33, no. 22, pp. 2999-3003, 1977.

[8] E. A. Katz, "Fullerene thin films as photovoltaic material," in Nanostructured Materials for Solar Energy Conversion, pp. 361443, Elsevier, 2006.

[9] J. A. Pople, M. J. Frisch, G. W. Trucks et al., "Gaussian Inc., 2004 Gaussian 03W (Revision C.01)," Gaussian Inc., Wallingford, Conn, USA, 2003.

[10] W. J. Pietro, M. M. Francl, W. J. Hehre, D. J. Defrees, J. A. Pople, and J. S. Binkley, "Self-consistent molecular orbital methods. 24. Supplemented small split-valence basis sets for second-row elements," Journal of the American Chemical Society, vol. 104, no. 19, pp. 5039-5048, 1982.

[11] K. D. Dobbs and W. J. Hehre, "Molecular orbital theory of the properties of inorganic and organometallic compounds 5. Extended basis sets for first-row transition metals," Journal of Computational Chemistry, pp. 861-879, 1987.
[12] A. D. Becke, "Density-functional exchange-energy approximation with correct asymptotic behavior," Physical Review, vol. 38, pp. 3098-3100, 1988.

[13] A. D. Becke, "Density-functional thermochemistry-III. The role of exact exchange," The Journal of Chemical Physics, vol. 98, no. 7, pp. 5648-5652, 1993.

[14] C. Lee, W. Yang, and R. G. Parr, "Development of the ColleSalvetti correlation-energy formula into a functional of the electron density," Physical Review, vol. 37, pp. 785-789, 1988.

[15] A. A. Al-Amiery, H. D. Jaffar, H. R. Obayes et al., "Thermodynamic studies on 4-aminocoumarin tautomers," International Journal of Electrochemical Science, vol. 7, pp. 8468-8472, 2012.

[16] J. H. Naama, G. H. Alwan, H. R. Obayes et al., "Curcuminoids as antioxidants and theoretical study of stability of curcumin isomers in gaseous state," Research on Chemical Intermediates, vol. 39, no. 9, pp. 4047-4059, 2013.

[17] A. D. Becke, "Density-functional thermochemistry-V. Systematic optimization of exchange-correlation functionals," Journal of Chemical Physics, vol. 107, no. 20, pp. 8554-8560, 1997.

[18] S. W. Benson, Thermochemical Kinetics, Wiley and Sons, New York, 1968.

[19] R. Berger and M. Klessinger, "Algorithms for exact counting of energy levels of spectroscopic transitions at different temperatures," Journal of Computational Chemistry, vol. 18, no. 10, pp. 1312-1319, 1997.

[20] G. Zheng, H. A. Witek, P. Bobadova-Parvanova et al., "Parameter calibration of transition-metal elements for the spin-polartaed self-consistent-charge density-functional tightbinding (DFTB) Method: Sc, Ti, Fe, Co, and Ni," Journal of Chemical Theory and Computation, vol. 3, no. 4, pp. 1349-1367, 2007.

[21] H. R. Obayes, "Theoretical study for the preparation of new buckyballs from the cyclic dimerization reaction of two molecules corannulene, coronene and circulene aromatic compounds," Journal of Engineering \& Technology, vol. 31, no. 5, pp. 594-602, 2013.

[22] H. R. Obayes, A. A. Al-Amiery, H. D. Jaffar et al., "Theoretical study for the preparation of sub-carbon nano tubes from the cyclic polymerization reaction of two molecules from corannulene, coronene and circulene aromatic compounds," Journal of Computational and Theoretical Nanoscience, vol. 10, pp. 24592463, 2013. 

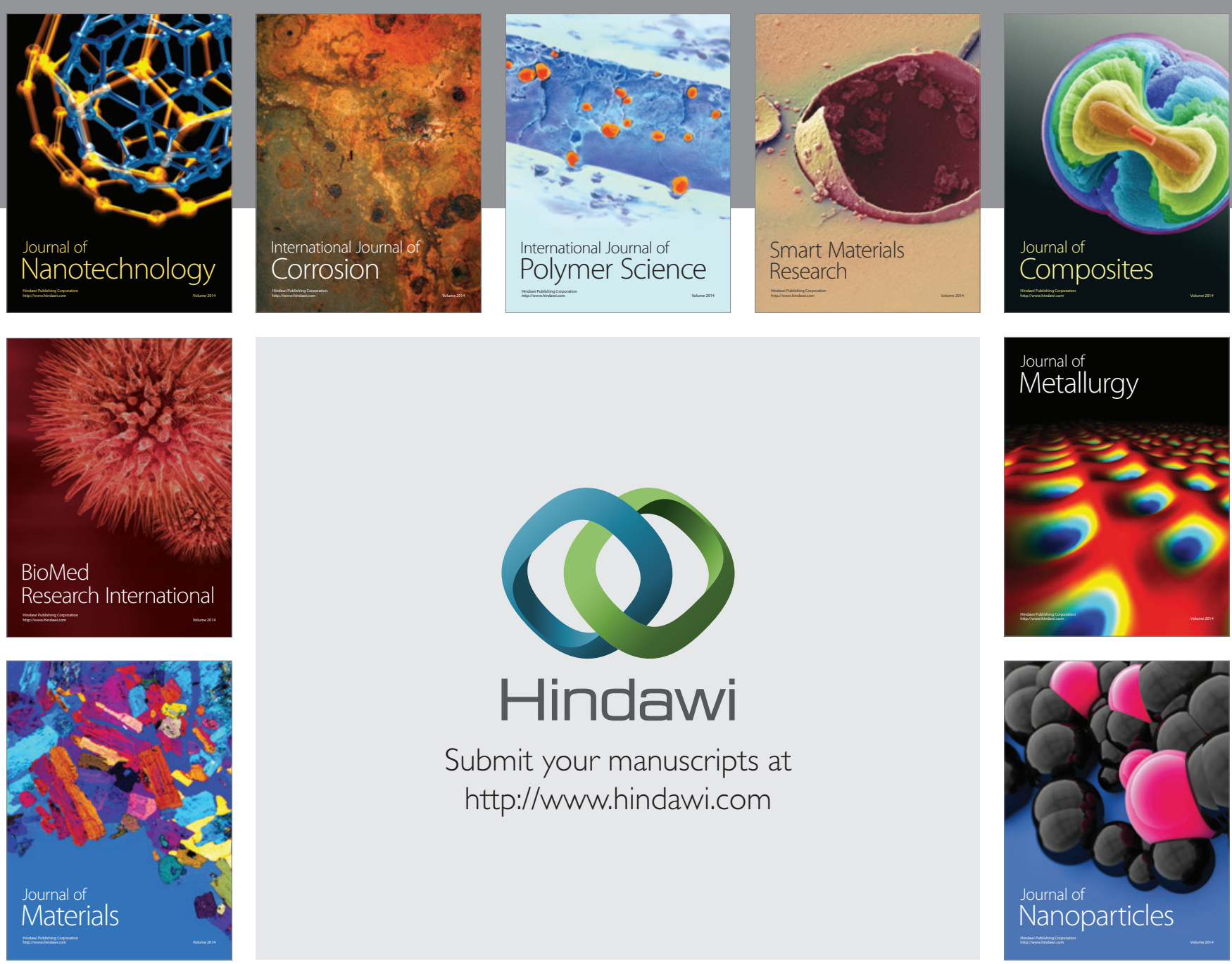

Submit your manuscripts at http://www.hindawi.com
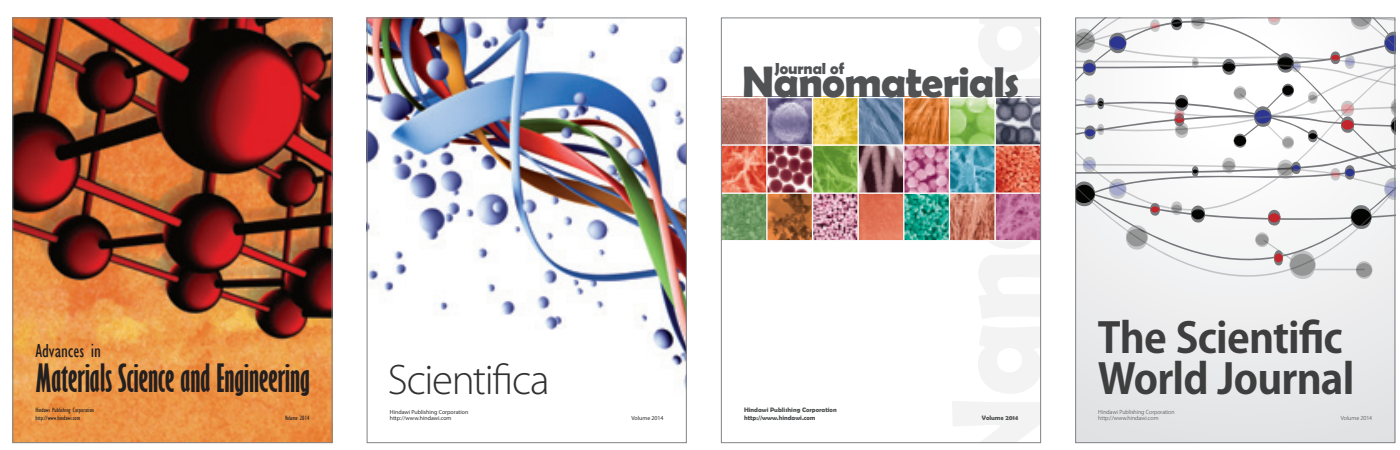

\section{The Scientific World Journal}
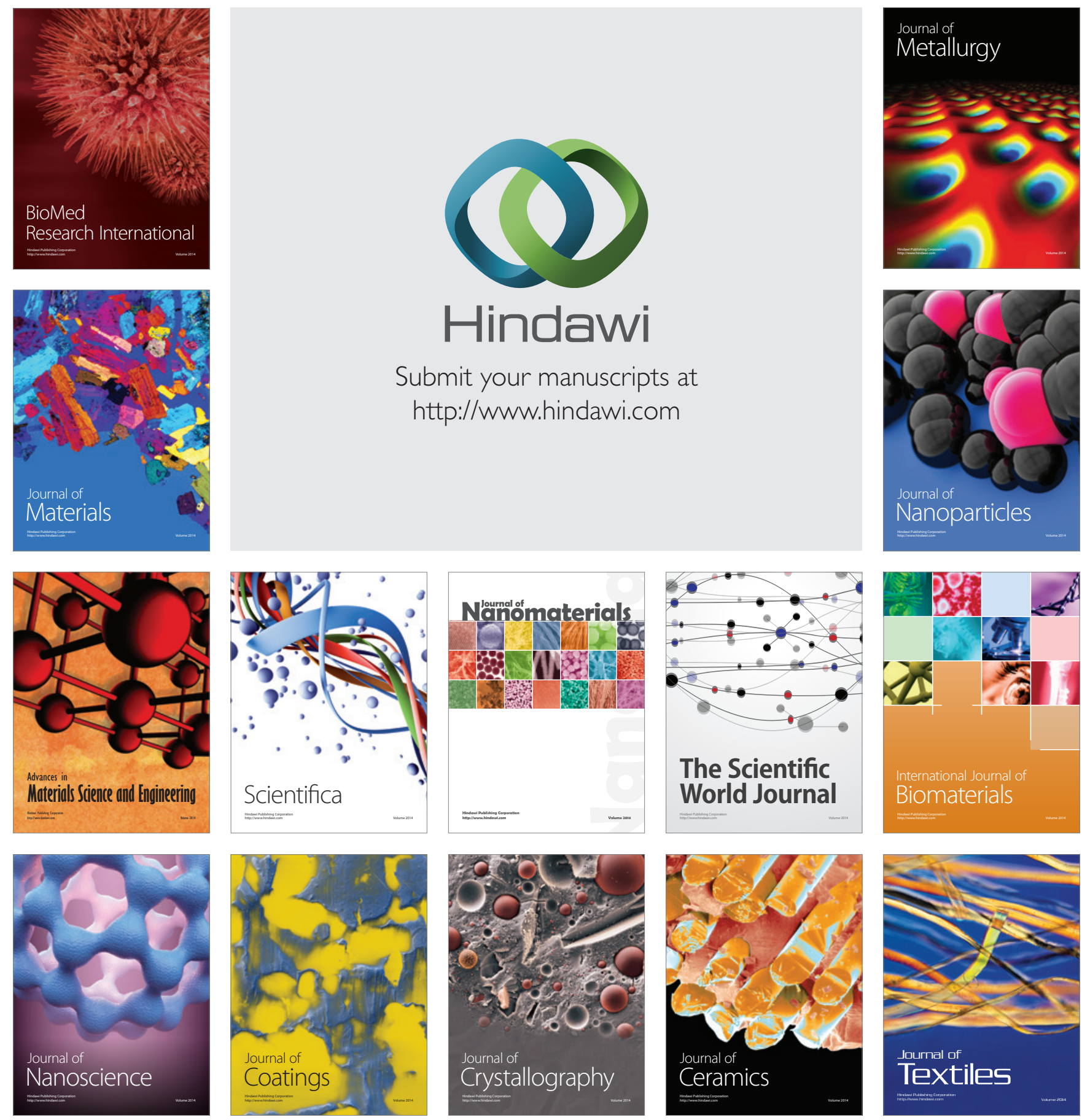